\title{
Popularity puts growing strain on Brussels
}

Freiberg. Research administrators were told last week that the European Commission needs the backing of the academic community if its attempts to sharpen the focus of projects funded under its next five-year Framework rescarch programme are to succeed in the face of political challenges.

The warning came from Graham Stroud, head of the commission's research management department, in an address to a meeting organized by KOWI, the German organization of European Union liaison officers, held in Freiberg, east Germany. The commission is proposing that the number of research lines be significantly reduced in the next Framework programme, due to start in 1998, partly to increase the currently low success rate of applications.

But Stroud warned that the European Parliament and Council of Ministers, both of which must approve the programme, could demand an increase in the number of research lines to promote national interests. Researchers could help by lobbying politicians in their own countries, to impress on them the importance of not trying to spread research money too thinly, he said.

The research directorate of the commission has become a victim of its own success. According to its 1996 annual report published last week, 24,000 proposals involving more than 100,000 participants were received last year. This represents nearly a tripling of workload in the past four years, during which time the number of staff at the commission has increased by only around 20 per cent.

This places a strain on the evaluation process, said Stroud, and has also caused the success rate of applications to plummet. It now averages 20 per cent, and in some programmes is as low as 6 per cent. The commission wants to raise the average success rate to one in three, a figure agreed with representatives of the research community during a seminar on programme management this summer.

The commission is already taking steps to try to control the situation, Stroud told the meeting. It plans to reduce the average time for approving applications from five to four months, in line with the speed of the most efficient national research councils in Europe. It is also extending to more programmes a newly introduced system for weeding out ineligible applications in advance.

But in the end "all this will only be fiddling at the edges", he said. "Everyone knows that the only way to get things under control is to reduce the number of programmes and to focus them." Member states agree with this in principle. Restricting the number of programmes heads the list of most countries' position papers on the fifth Framework programme, which takes over when the fourth programme finishes at the end of 1998 (see Nature 381, 634; 1996).

Yet commission officials remember the fate of a proposal that there should be only six research programmes in the fourth Framework programme, which was put forward by the former research commissioner, Filipo Pandolfi. The number had risen to 15 by the time all member states felt that they were benefiting individually, and gave the programme their approval.

The meeting in Freiberg also learned that the future remains unclear for the task forces set up last year to coordinate the research efforts of the European Commission in particular technological areas. JeanMarie Martin, director of the commission's Environment Institute, based at Ispra in northern Italy, who heads the task force on water, said that the task forces still had no clear idea about how they were likely to fit into the decision-making process of the commission. And he said there was still no word on how they were to be financed.

The research commissioner, Edith Cresson, suggested a year ago that the task forces' first round of work should be supported by 'top-up funds' held in reserve for the fourth Framework programme. However, because of the European beef crisis, the amount of money likely to be available has fallen from ECU700 million (US\$881 million) to around ECU200 million (US\$252 million). The Council of Ministers has yet to vote on whether all or none of this potential fund should be approved. A decision is expected before the end of the year. But it is likely to come too late for the 1997 budget. Alison Abbott

\section{UK medical chief suggests 'safe' does not mean 'no risk'}

London. The chief medical officer of the UK's Department of Health - currently embroiled in political controversy over whether British beef is safe to eat - has suggested standardizing the way in which risks are described to the public on a scale based on their severity.

Kenneth Calman proposes in his annual report, published last week, that the word 'safe' should, if used, "be seen to mean negligible" - itself defined as "an adverse event occurring at a frequency below one per million". It should not, he adds, "imply no, or zero, risk".

Such a definition of negligible risk would, for example, include the chances of dying from being hit by lightning, or from the radiation released by a nuclear power station. It would also, on the basis of the most recent scientific evidence, include the chances of contracting Creutzfeldt-Jakob disease (CJD) by eating meat infected with bovine spongiform encephalopathy (BSE).

Calman's suggestions are put forward in a section of his report on "topics of particular importance". They are, he says, an attempt to "present a vocabulary for debate", adding that the perception of risk by the individual is "the most interesting but most difficult aspect of understanding risk".

He proposes dividing events into six categories, based on the chances of each occurring to an individual within any one year. These start with events of "high risk", where the risk estimate is considered to be greater than one in 100 , and descend in a series of steps through "moderate", "Iow", "very low", and "minimal" to "negligible"

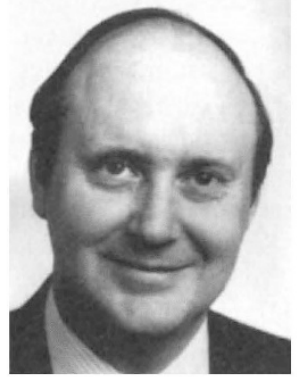
risk Calman: tackling risk passing events whose likelihood is an order of magnitude smaller than those in the previous category.

Calman acknowledges that any classification of a particular risk needs to be qualified by other words that may be equally important. These include whether the risk is avoidable or unavoidable; whether it is justifiable; whether it is acceptable or unacceptable (the latter meaning that it "would not be tolerated except for special reasons - such as the use of unproven medical treatment as a therapy of last resort"); and whether the risk is "serious".

His categorization of risk has received a sceptical response from some public-interest and environmentalist groups. While acknowledging the importance of a more rational approach, these are concerned that events with any danger attached should not be officially labelled as 'safe' - even if the risks are less than one in a million.

But Calman's scheme has, in general, been welcomed by industrial representatives such as those from the pharmaceutical industry, frustrated at what they argue to be the public's inability to distinguish the relative dangers posed by different kinds of risks. Britain's beef industry, for example, has slumped in the wake of the BSE scare, even though only about a dozen cases of $\mathrm{CJD}$ have been linked to 'mad cow disease' - in a human population of almost 60 million. 